\title{
Treatment of Lymphatic Malformations with the mTOR Inhibitor Sirolimus: A Systematic Review
}

\author{
Susanne Wiegand, MD, Gunnar Wichmann, MD, and Andreas Dietz, MD
}

\begin{abstract}
Background: Extensive lymphatic malformations are low-flow vascular malformations that can cause devastating complications. Treatment of these malformations is challenging. This systematic review presents current use of sirolimus in patients with extensive lymphatic malformations.

Methods: MEDLINE and Google scholar search was conducted for studies on sirolimus treatment of lymphatic malformations up to July 2017. Search items included "lymphatic malformation," "lymphangioma," "cystic hygroma," "vascular malformation," "low-flow malformation," "sirolimus," "rapamycin," and "mTOR inhibitor."

Results: Twenty studies, including 71 patients receiving sirolimus, were included into this review. Forty-five patients had lymphatic malformations, eight patients venolymphatic malformations, and 19 patients capillarylymphatico-venous malformations. Sirolimus led to a partial remission of disease in 60 patients, three patients had a progressive disease, and the outcome of eight patients was not reported. Dosing, target trough level, and duration of treatment differed between the studies. Common adverse effects were hyperlipidemia and neutropenia.

Conclusions: Available literature indicated that sirolimus therapy might be effective for lymphatic malformations. However, further randomized controlled studies are required to analyze the efficacy and long-term adverse events and to clarify the potential role for sirolimus in the management of lymphatic malformations.
\end{abstract}

Keywords: lymphatic malformation, sirolimus, rapamycin

\section{Introduction}

$\mathbf{V}$

ASCULAR ANOMALIES SUMMARIZE a wide spectrum of diseases, which are classified by use of the system of the International Society for the Study of Vascular Anomalies (ISSVA), which divides vascular tumors from vascular malformations based on clinical, genetic, and pathologic characteristics. Lymphatic malformations are low-flow vascular anomalies of the lymphatic system that most frequently affect the head and neck and are typically present at birth. Only some become manifest at a later stage. Their precise pathogenesis is still unknown. ${ }^{1}$ The incidence of lymphatic malformations is estimated to 1.2-2.8 lymphatic malformations per 1000 births $^{2}$ and 2.8 patients per 100,000 hospital admissions. ${ }^{3}$ Their growth is proportional to the patients' body growth, but related to infection, trauma, and hormonal changes there could be further enlargement.

Histologically, lymphatic malformations consist of cysts which are lined by a single layer of endothelium and contain an amorphous collection of lymph. ${ }^{4}$ Depending upon the location and surrounding tissues the cysts can vary in size, and therefore, lymphatic malformations can be characterized into macrocystic (cyst diameter $>1 \mathrm{~cm}$ ), microcystic (cyst diameter $<1 \mathrm{~cm}$ ), or mixed.

The clinical presentation of patients with lymphatic malformations can be diverse ranging from focal swelling to large diffusely infiltrating masses with compromise of adjacent structures. ${ }^{5}$ Symptoms depend on localization and size of the malformation and can include airway obstruction, neurovascular dysfunction, and deformity. The correct diagnosis of lymphatic malformation is key to appropriate therapy. Radiologic studies, including computed tomography, magnetic resonance imaging, and ultrasound, were necessary to define the extent and type of malformation, as well as its relationship to vital structures. ${ }^{6}$

Treatment of lymphatic malformation varies and, therefore, should be individualized for each patient. This personalized approach has to address functional restriction, esthetic

Department of Otolaryngology, Head and Neck Surgery, University of Leipzig, Leipzig, Germany. 
impairment, and pain. In case of life-threatening functional impairment early intervention is mandatory. In macrocystic lymphatic malformations, surgery and sclerotherapy are effective. Surgery of microcystic lymphatic malformations remains challenging due to their infiltrative nature. Sclerotherapy of microcystic lymphatic malformations is often impossible. ${ }^{7}$ As especially large microcystic and mixed malformations are still a therapeutic challenge, pharmaceutical treatment is very desirable.

The mammalian target of rapamycin (mTOR) is an evolutionarily highly conserved serine/threonine protein kinase. mTOR activates protein synthesis, leading to numerous cellular processes, including cell proliferation and increased angiogenesis. Deregulation of the mTOR pathway has been implicated in several diseases such as cancer, diabetes, neurological diseases, and genetic disorders. mTOR is also suspected to play a key role in the pathogenesis of various vascular anomalies. ${ }^{8}$ The first compound inhibiting mTOR, sirolimus (rapamycin), was identified in the 1970s. ${ }^{9}$ It is a natural macrolide isolated from a bacteria strain of the Streptomyces genus (Streptomyces hygroscopicus) collected on Easter island (Rapa Nui). Although rapamycin was isolated as an antibiotic and antifungal agent, subsequent studies have revealed impressive cytostatic, antiproliferative, and immunosuppressive properties. Rapamycin was approved in 1999 by the US Food and Drug Administration (FDA) for use in the prevention of kidney allograft rejection. ${ }^{10}$

In 2015, the FDA approved sirolimus as first drug to treat lymphangioleiomyomatosis, a rare, progressive lung disease that primarily affects women of childbearing age. A role for sirolimus to treat vascular malformations is supported by the fact that sirolimus causes a decrease in vascular endothelial growth factor (VEGF), which is a known key regulator in lymphangiogenesis and angiogenesis. The first report on the successful use of sirolimus as an antiangiogenetic agent was published in 2010. ${ }^{11}$ However, data about the use of sirolimus in treatment of patients with vascular anomalies are still rare. This review presents the current knowledge on sirolimus therapy in lymphatic malformations.

\section{Materials and Methods}

This study was designed as a systematic review. Inclusion criteria were as follows: original reports (study, case series, case reports, and posters) describing systemic treatment of lymphatic malformations with sirolimus (rapamycin) in humans. A search was performed for all case reports, retrospective case series, original articles, and randomized clinical trials pertaining to the use of sirolimus in the treatment of lymphatic malformations, venolymphatic malformations, and capillary-lymphatico-venous malformations. The search was conducted using MEDLINE and Google Scholar, employing the terms "lymphatic malformation," "lymphangioma," "cystic hygroma," "vascular malformation," "low-flow malformation," "sirolimus," "rapamycin," and "mTOR inhibitor." The search was concluded in July 2017 at the end of our study period.

In addition, the reference sections of suitable sources were searched for related articles. Language or study design restrictions were not used. Whenever titles and/or abstracts fit our search terms, abstracts were reviewed to exclude irrelevant studies. Review articles, duplicate publication, or reports with insufficient information (full text not accessible, full text did not contain any raw data) were excluded. The remaining articles were carefully checked to determine whether they contained data that were applicable to our study. In cases where articles reported the same data, only information from the most recent publication was included, unless data could only be obtained from older reports. Reports on generalized lymphatic anomaly, Gorham-Stout disease, lymphangiomatosis, lymphangiectasia, and chronic lymphedema, as well as reports on topical treatments, were excluded.

Through these methods, 20 articles were identified, containing a total of 71 cases in which sirolimus was used to treat lymphatic malformations, venolymphatic malformations, and capillary-lymphatico-venous malformations. ${ }^{8,12-30}$ After identifying these articles, all text and figures were carefully assessed for relevant data. The following information on study characteristics and clinical treatments was extracted from all included studies: publication metrics (name of first author and year of publication), subject information (age, gender, and localization of malformation), and treatment information (sirolimus dose, planned target trough level, treatment duration, treatment outcomes, additional therapies, and adverse events).

\section{Results}

Included studies and clinical characteristics of the patients

Twenty studies, including 71 patients treated with sirolimus for lymphatic malformations, venolymphatic malformations, and capillary-lymphatico-venous malformations, were included into this review. ${ }^{8,12-30}$ Most studies were retrospective case series or case reports, and there was only one phase II trial. In all, 16 publications about 45 patients with lymphatic malformations were identified (Table 1), ${ }^{8,12-26}$ five publications about eight patients with venolymphatic malformations (Table 2), ${ }^{12,21,27-29}$ and four publications about 18 patients with capillary-lymphatico-venous malformations (Table 3). 8,12,29,30 All patients had extensive malformations, which were distributed about the whole body. The age of the patients ranged from newborn to 64 years; however, most of the patients were children. All patients have been treated before, and most of them have been heavily pretreated. Although some patients had shown a minimal response to prior therapies, these were insufficient (Tables 1-4).

\section{Treatment with sirolimus}

In most studies, sirolimus was administered orally at an initial dosage of $0.8 \mathrm{mg} / \mathrm{m}^{2}$ per dose, twice daily at 12-hour intervals. $8,12-14,16,20,23,24,26,29$ The dose was then subsequently adjusted to reach the planned target blood level. In three studies a different dose was used; sirolimus was initially administered orally at a dosage of $0.1 \mathrm{mg} / \mathrm{kg}$ per 24 hours twice daily, ${ }^{30}$ $0.05 \mathrm{mg} / \mathrm{kg}$ twice daily, ${ }^{21}$ or $0.07 \mathrm{mg} / \mathrm{kg}$ twice daily. ${ }^{17}$ In six publications, the initial dose of sirolimus was not reported. ${ }^{15,18,19,22,25,28}$

The target blood level of sirolimus was similar $(\leq 15 \mathrm{ng} / \mathrm{mL})$, but slightly differed between the studies. The target blood level was $10-15 \mathrm{ng} / \mathrm{mL}$ in seven studies, $8,12,18,22,23,26,275-15 \mathrm{ng} / \mathrm{mL}$ in four studies, ${ }^{21,24,29,30} 10-13 \mathrm{ng} / \mathrm{mL}$ in one study, ${ }^{16}$ and $4-8 \mathrm{ng} / \mathrm{mL}$ in one study. ${ }^{20}$ In seven studies, the authors did not 


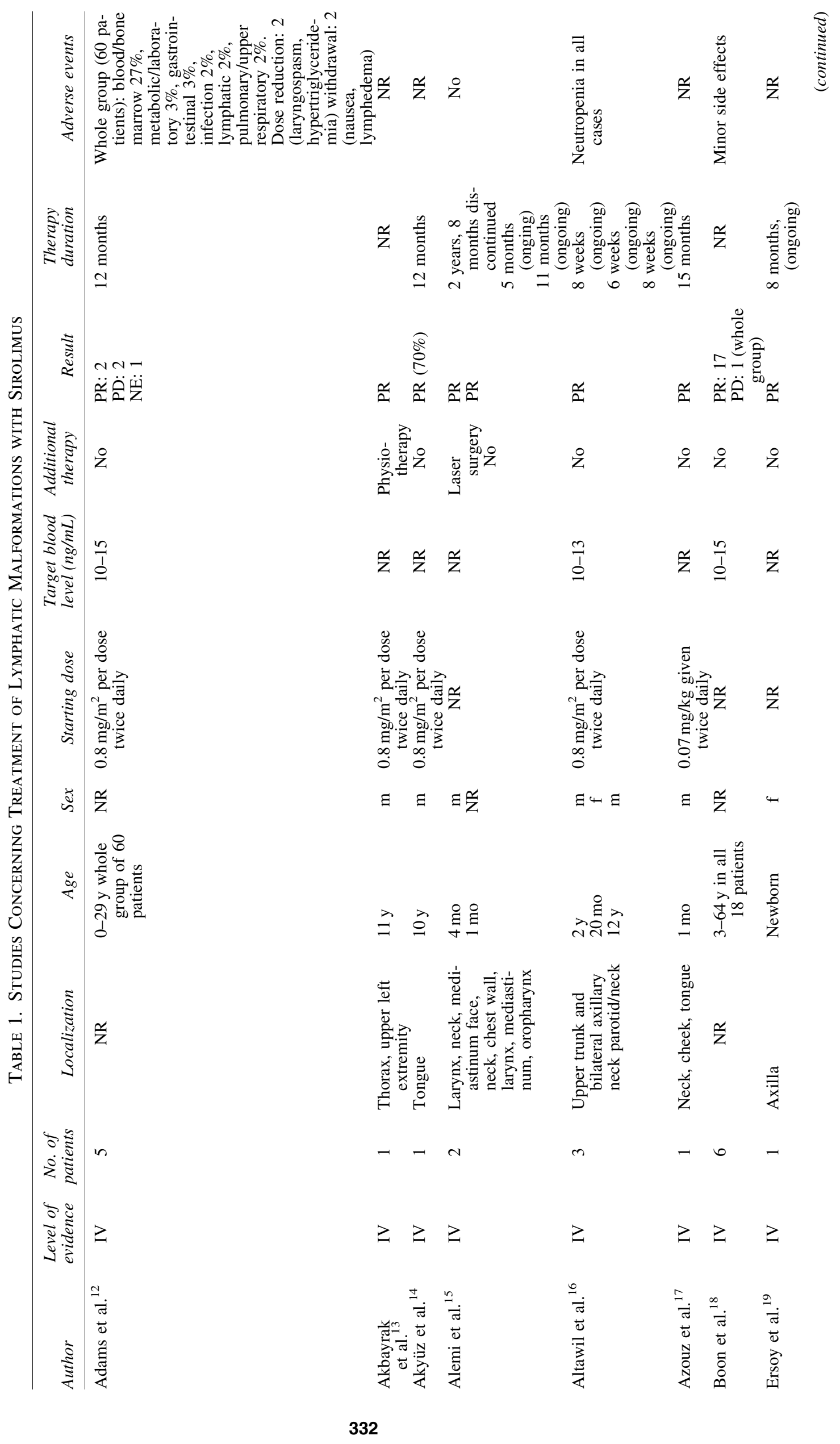




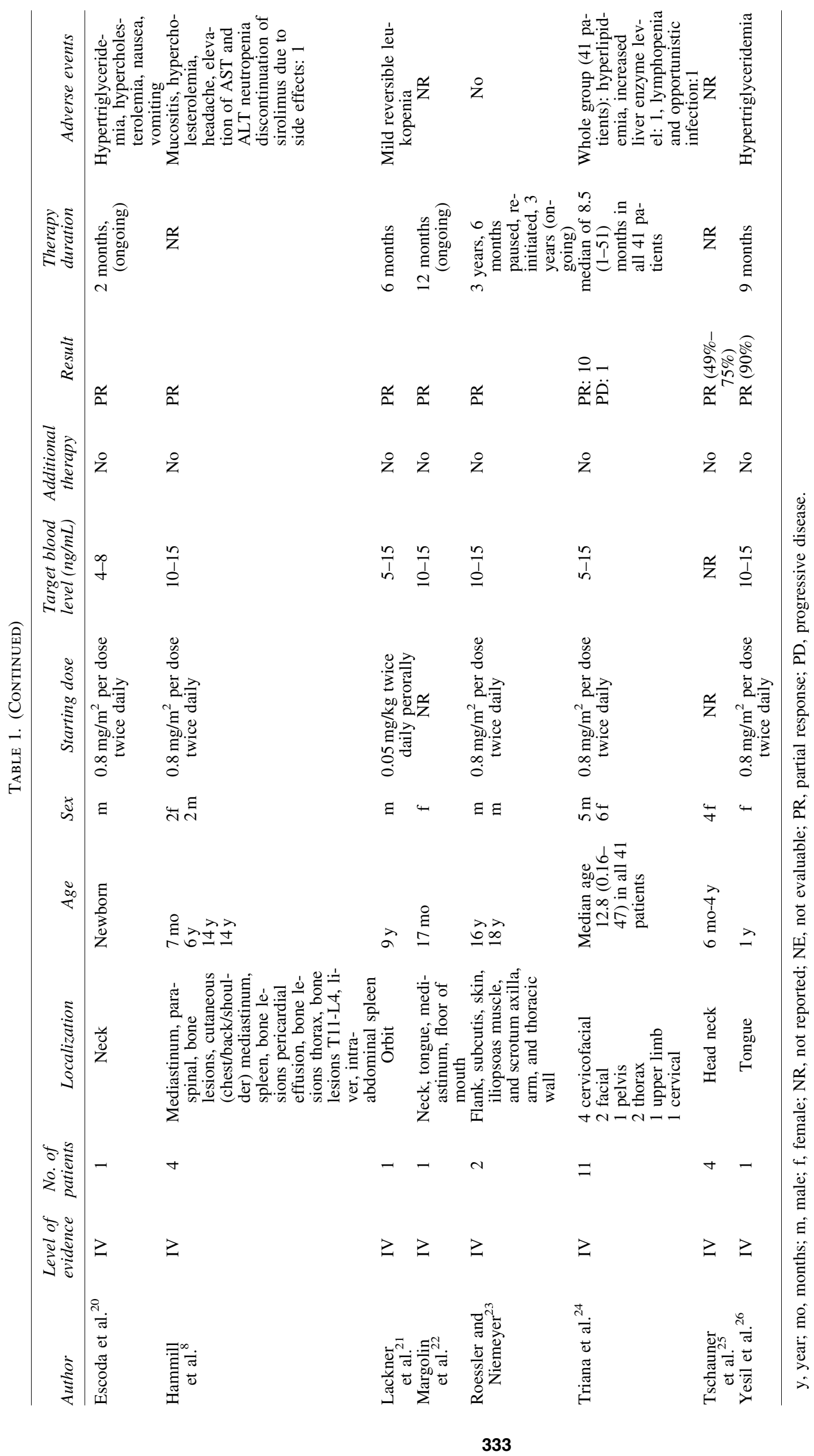




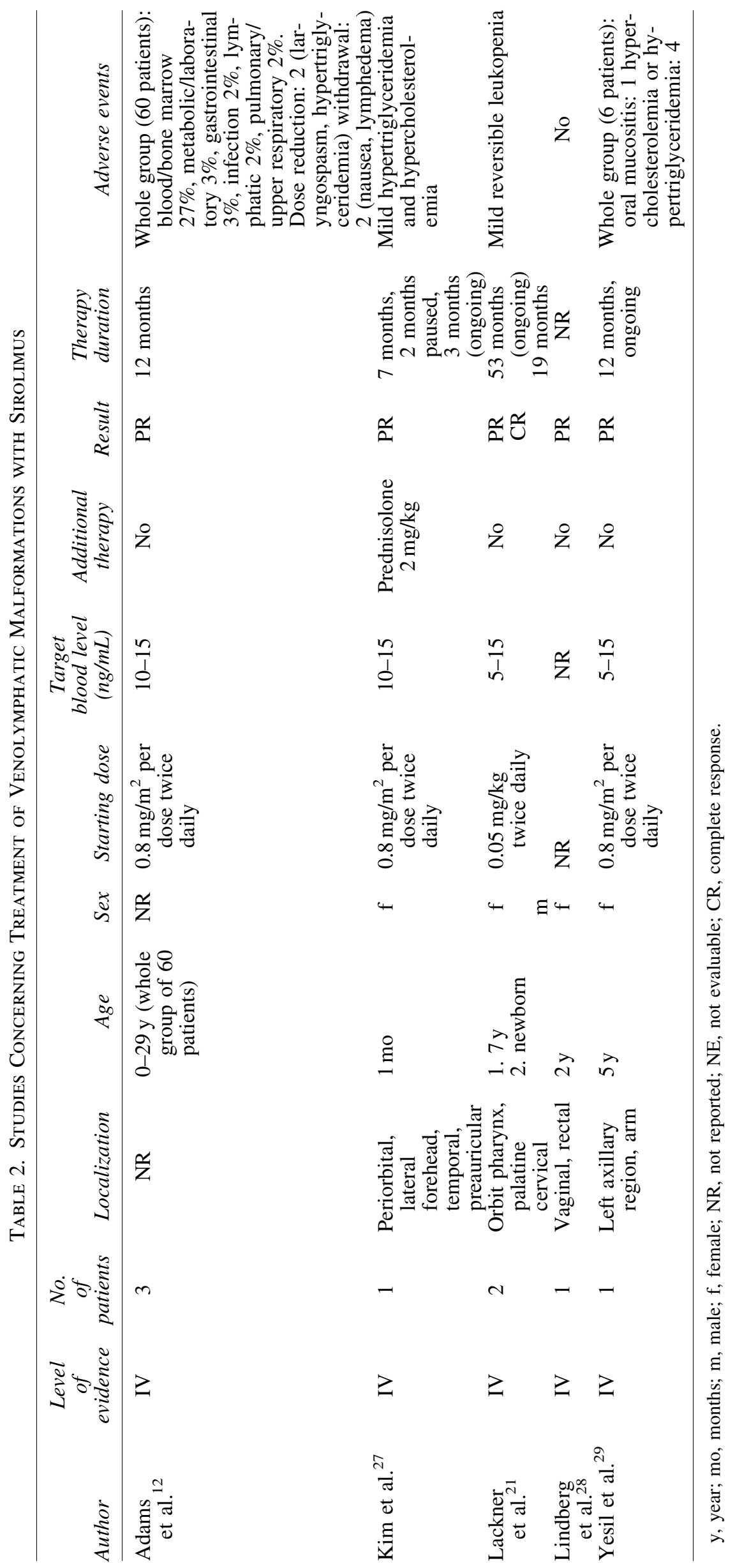




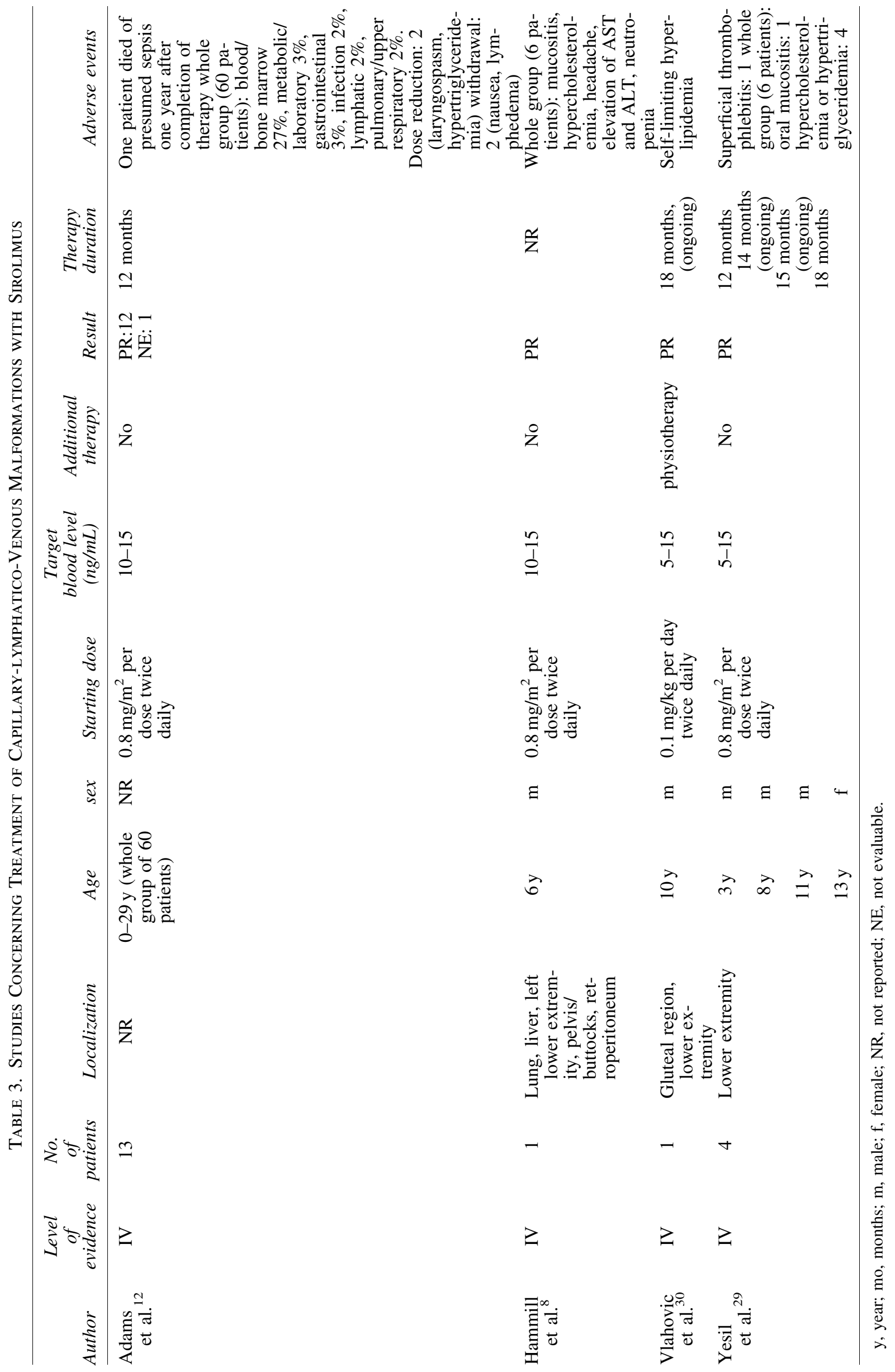


Table 4. Patient and Treatment Characteristics

\begin{tabular}{|c|c|c|c|}
\hline & $L M$ & $C L V M$ & $V L M$ \\
\hline \multicolumn{4}{|l|}{ Sex } \\
\hline Male & 17 & 5 & 1 \\
\hline Female & 16 & 1 & 4 \\
\hline Not reported & 12 & 12 & 3 \\
\hline \multicolumn{4}{|c|}{ Age at treatment initiation } \\
\hline$<6$ months & 5 & - & 2 \\
\hline 6 months -2 years & 5 & - & 1 \\
\hline $3-6$ years & 1 & 1 & 一 \\
\hline $7-12$ years & 4 & 1 & 1 \\
\hline $12-18$ years & 4 & - & - \\
\hline Not reported & 26 & 16 & 4 \\
\hline \multicolumn{4}{|l|}{ Response to treatment } \\
\hline Partial response & 35 & 17 & 7 \\
\hline Complete response & - & - & 1 \\
\hline Progressive disease & 3 & - & - \\
\hline Not reported & 7 & 1 & - \\
\hline
\end{tabular}

LM, lymphatic malformations; CLVM, capillary-lymphaticovenous malformations; VLM, venolymphatic malformations.

mention the target blood level of sirolimus. ${ }^{13-15,17,19,25,28}$ Not in all studies the planned target trough level for sirolimus was achieved. For example, Kim et al. ${ }^{27}$ reported a marked clinical response at a trough level for sirolimus of $3.5 \mathrm{ng} / \mathrm{mL}$, which was below the planned target trough of $10-15 \mathrm{ng} / \mathrm{mL}$. However, because of the response, the dose was kept at $0.8 \mathrm{mg} / \mathrm{m}^{2}$. The average time to response was reported only in few studies, but seems to differ. Hammill et al. ${ }^{8}$ reported that the average time to response was 25 days, but ranged from eight to 65 days.

The studies also varied regarding the duration of sirolimus treatment. In 15 studies, data on the duration of treatment were presented. ${ }^{14-17,19-24,26,27,29,30}$ In 16 patients sirolimus was not withdrawn at last follow-up, which ranged from six weeks to 53 months.

Data on associated treatments were available for four cases. $^{13,15,27,30}$ In one patient sirolimus was associated with prednisolone $2 \mathrm{mg} / \mathrm{kg}^{27}$ This patient showed a better response under combined therapy than under sirolimus alone. In one patient sirolimus treatment was combined with laser surgery, ${ }^{15}$ and in two patients additional physiotherapy was reported. ${ }^{13,30}$

\section{Efficacy of sirolimus treatment}

In most of the studies, the authors did not report the exact response rate, but used terms like "marked improvement," "significant volume reduction," or "significant decrease." Therefore, the results were not comparable. The outcome of 38 patients with lymphatic malformations, all patients with venolymphatic malformations, and 17 patients with capillarylymphatico-venous malformations was reported (Tables 1-4).

In all, 60 of 63 patients with a reported treatment result showed a response to sirolimus. All patients with venolymphatic malformations responded to sirolimus; in one of these patients a complete response was reported. In the group of patients with capillary-lymphatico-venous malformations, a partial response was reported in 16 patients; one patient was lost to follow-up. Of the patients with lymphatic malformations, 35 had a partial response, one showed no response, and two had a progressive disease. In one patient the outcome was not evaluable. Boon et al. ${ }^{18}$ analyzed a group of 18 patients with vascular malformations treated with sirolimus; six of these patients had lymphatic malformations. They reported that $17 / 18(94 \%)$ of patients experienced almost complete relief of pain and symptoms and that magnetic resonance imaging showed a decrease in most of the patients' malformations. However, detailed information on the patients with lymphatic malformations was missing.

\section{Adverse effects of sirolimus treatment}

Fourteen studies commented on adverse events associated with and probably being a result of sirolimus therapy. $8,12,15,16,18,20,21,23,24,26-30$ In three studies patients $(n=5)$ experienced no side effects. ${ }^{15,23,28}$ In the other 11 studies different adverse effects were reported. $8,12,16,18,20,21,24,26,27,29,30$ In the study of Adams et al., ${ }^{12}$ who analyzed a cohort of 57 patients with different vascular anomalies, the most common adverse events attributed to sirolimus were toxic effects on blood/bone marrow in $27 \%$ of the patients, whereas other toxicities were seldom observed (metabolic/laboratory 3\%, gastrointestinal 3\%). This was also true for sirolimusassociated infection at $2 \%$, lymphatic at $2 \%$, and pulmonary/ upper respiratory at $2 \%$. In the other studies the most common adverse effects were hyperlipidemia and neutropenia.

Dose reductions or discontinuation of medication due to side effects were reported only in two studies. ${ }^{8,12}$ Adams et al. ${ }^{12}$ stated about dose reductions being required in two of 57 patients, and further two patients were taken off study medicine secondary to toxicity. Hammill et al. ${ }^{8}$ also reported about one patient who discontinued sirolimus due to side effects. Furthermore, in the study of Adams et al. ${ }^{12}$ one patient with a capillary-lymphatico-venous malformation died of presumed sepsis one year after completion of therapy possibly related to the prior treatment.

\section{Discussion}

The use of sirolimus in pharmaceutical therapy of lymphatic malformations is not well established, but based on published data about few and mostly limited numbers, and grade of adverse events appears to be safely applicable. Despite only seldom observed complete response of lymphatic malformations to sirolimus, most studies highlighted that the majority of patients experienced a partial response and had benefit from its pain-relieving action. Therefore, sirolimus may be a useful option for the treatment of extensive lymphatic malformations that always is challenging.

Specific recommendations regarding treatment for the whole patient group and the sequence of treatments cannot be made due to variations in the size and location of malformations. The goal of treatment is to maintain functionality, control associated symptoms, and preserve esthetic integrity. The treatment should be individualized and the treatment decision should be based on the characteristics of the lymphatic malformation, as well as the age of the patient and the wishes of the patients and parents.

In extensive lymphatic malformations, it is often impossible to perform a complete surgical resection but preserve the function. Especially the infiltrative nature of microcystic lymphatic malformations renders complete surgical excision technically demanding, and sirolimus may find, in particular, a place in treatment of these lesions. Sclerotherapy is a therapeutic 
option particularly in macrocystic lymphatic malformations. ${ }^{7}$ Watch-and-wait is a reasonable option, especially if there are no or little symptoms or functional deficits. However, the potential risk of acute enlargement of the lymphatic malformation secondary to infections or spontaneous or traumatic hemorrhage is always to be kept in mind. Pharmacologic treatment with different medications like sildenafil and propranolol has been examined to treat extensive lymphatic malformations without striking success. ${ }^{31-35}$ Therefore, the potential utilization of sirolimus should be investigated.

The first report on the use of sirolimus in patients with lymphatic malformations was published in 2011. ${ }^{8}$ The complete mechanism of action is not clear. VEGF is known to play a role in lymphangiogenesis by upregulating mTOR signaling followed by proliferation. Recent studies have shown that sirolimus inhibits lymphangiogenesis by decreasing synthesis and promoting degradation of VEGF receptor $3{ }^{36}$ Since 2011 , several case reports and case series have been published regarding this topic. In our systematic review 20 publications, including 71 patients with lymphatic malformations treated with sirolimus, could be identified. ${ }^{8,12-30}$ Some of these publications included patients with other vascular anomalies like venous or arteriovenous malformations or other lymphatic diseases. $8,12,18,21,24,29$ The evaluation of these diseases was not the goal of this review, and these patients were therefore not included in this analysis.

In all, the data reported in the included studies were heterogeneous and were not reported in a standardized manner. Furthermore, incomplete reporting limited our ability to compare the results of the analyzed studies. For example, the outcome after therapy was not reported for all patients, but in those cases with a reported result, 95\% showed a response to sirolimus of a different extent. Only in three cases a progressive disease was reported. However, since most of the studies present qualitative and not quantitative response data and there was much heterogeneity in terms of definition of response and measurement of response, the results were difficult to compare.

The dosage of sirolimus and the duration of treatment also differed since no evidence-based guidelines exist for proper dosing of sirolimus in patients with lymphatic malformations or duration of treatment. In most studies, an initial dosage of $0.8 \mathrm{mg} / \mathrm{m}^{2}$ sirolimus per dose administered twice daily at 12 hour intervals was used. $8,12-14,16,20,23,24,26,29$ The target blood level was $5-15 \mathrm{ng} / \mathrm{mL}$ or $10-15 \mathrm{ng} / \mathrm{mL}$ in most of the studies $8,12,18,21-24,26,27,29,30$; however, some studies reported difficulties in maintaining the desired sirolimus level. Margolin et al. ${ }^{22}$ reported about a 17-month-old infant who had a significant reduction in size of the lymphatic malformation, but rarely met the sirolimus target trough level range of 10$15 \mathrm{ng} / \mathrm{mL}$ and more often had a level of $<10 \mathrm{ng} / \mathrm{mL}$ or even $<2 \mathrm{ng} / \mathrm{mL}$. Kim et al. ${ }^{27}$ reported a marked clinical response in a neonate with a blood level of $3.5 \mathrm{ng} / \mathrm{mL}$; therefore, the investigators kept this dose stable. These examples show that even a lower dose of sirolimus might offer the same therapeutic benefit while minimizing adverse effects. This might be true, as there doesn't seem to be an association between serum levels and grade of response.

Sirolimus is FDA approved for use in pediatric kidney transplantation in patients aged 13 years and older. Therefore, it is not known what dose of sirolimus is safe and effective in newborns and small children. In many studies, the dosage of sirolimus and target blood level were not mentioned. Until now, the optimal dose of sirolimus, target blood level, and duration of treatment in patients with lymphatic malformations remain unclear. Additional studies are needed.

The safety of long-term use of sirolimus in organ transplant recipients has been demonstrated. However, patients and caregivers must be keenly aware of potential side effects of sirolimus. Main and most common adverse effects of sirolimus treatment are anemia, thrombocytopenia, leukopenia, and increases in triglyceride and cholesterol levels. ${ }^{37}$ Due to the intrinsic immunosuppressive potential of sirolimus, which is the reason for its use in transplant medicine, there is a high risk for infections. ${ }^{38}$ Other adverse effects associated with sirolimus include hemodynamic (e.g., hypertension), dermatologic (e.g., rash, mucositis), renal (e.g., proteinuria), and hormonal problems. ${ }^{39}$

This analysis demonstrated different adverse events in patients with lymphatic malformations receiving sirolimus although not all studies commented on adverse events associated with sirolimus therapy. Adverse effects reported were in most cases benign and manageable. However, they may affect quality of life and demand dose modification or drug withdrawal. There were only few reported cases without any side effects experienced when using the drug. Dose adjustments or treatment discontinuations due to drug toxicity were also reported in two studies. ${ }^{8,12}$ Side effects did not correlate with the blood level of sirolimus. Altawil et al. ${ }^{16}$ reported a case with fever and neutropenia, while the sirolimus level was $2.4 \mathrm{ng} / \mathrm{mL}$. Therefore, patients should be well educated on potential adverse effects, and the decision for the use of sirolimus should be based on individual patient characteristics and risk factors. Due to potential side effects, sirolimus should not be considered as treatment for small lymphatic malformations that respond to standard treatment.

This systematic review is not without limitations. Like all systematic reviews, there may be publication bias with respect to centers publishing good outcomes. The articles included in this study were case series or case reports from individual institutions and are prone to the bias involved with retrospective studies. Thus, the results are difficult to interpret. There is a small sample size which is due to the rarity of this condition. In addition, as these data were obtained from separate articles, there are wide variations in the clinical management and treatment durations. Numerous gaps exist in terms of the data being reported.

As further possible limitations of the present study, we can cite the low methodological quality of the included studies, the lack of randomized controlled trials, the heterogeneity regarding drug dosage, definition of response, measurement of response, and measurement of toxicity. The significant heterogeneity between the studies will limit the applicability of the findings. This is hardly surprising considering the differences in study populations and case selection between centers.

\section{Conclusions}

Although limited, this review suggests that sirolimus might be an effective treatment for patients with extensive lymphatic malformations and expands the range of therapeutic options. Randomized controlled trials are lacking, but would be needed to fully assess the therapeutic efficacy of sirolimus, especially as we know that some lymphatic malformations show a partial remission without any treatment. Questions remain regarding the correct timing for treatment 
initiation and discontinuation of sirolimus, dosing, the serum level to be achieved, and possible long-term side effects and their management.

This article is a systematic literature review and does not require review by an ethics committee for human subjects.

\section{Author Disclosure Statement}

No competing financial interests exist.

\section{References}

1. Wiegand S, Eivazi B, Barth PJ, von Rautenfeld DB, Folz BJ, Mandic R, Werner JA. Pathogenesis of lymphangiomas. Virchows Arch 2008; 453:1-8.

2. Filston HC. Hemangiomas, cystic hygromas and teratomas of the head and neck. Semin Pediatr Surg 1994; 3:147-159.

3. Smith RJ. Lymphatic malformations. Lymphat Res Biol 2004; 2:25-31.

4. Yaita T, Onodera K, Xu H, Ooya K. Histomorphometrical study in cavernous lymphatic malformation of the tongue. Oral Dis 2007; 13:99-104.

5. Wiegand S, Ott A, Zimmermann AP, Wilhelm T, Eivazi B, Werner JA. Localization of lymphatic malfomations of the neck. Lymphat Res Biol 2013; 11:101-103.

6. Wiegand S, Eivazi B, Zimmermann AP, Neff A, Barth PJ, Sesterhenn AM, Mandic R, Werner JA. Microcystic lymphatic malformations of the tongue-diagnosis, classification, and treatment. Arch Otolaryngol Head Neck Surg 2009; 135:976-983.

7. Wiegand S, Eivazi B, Zimmermann AP, Sesterhenn AM, Werner JA. Sclerotherapy of lymphangiomas of the head and neck. Head Neck 2011; 33:1649-1655.

8. Hammill AM, Wentzel MS, Gupta A, Nelson S, Lucky A, Elluru R, Dasgupta R, Azizkhan RG, Adams DM. Sirolimus for the treatment of complicated vascular anomalies in children. Pediatr Blood Cancer 2011; 57:1018-1024.

9. Morris RE. Rapamycins: Antifungal, antitumor, antiproliferative, and immunosuppressive macuolides. Transplant Rev 1992; 6:39-87.

10. "Sirolimus (marketed as Rapamune) Safety". FDA.gov. U.S. Food and Drug Administration. 11 June 2009. https:// www.fda.gov/Drugs/DrugSafety/PostmarketDrugSafety InformationforPatientsandProviders/ucm171884.htm. Retrieved 1 Aug 2016.

11. Blatt J, Stavas J, Moats-Staats B, Woosley J, Morrell DS. Treatment of childhood kaposiform hemangioendothelioma with sirolimus. Pediatr Blood Cancer 2010; 55:1396-1398.

12. Adams DM, Trenor CC 3rd, Hammill AM, Vinks AA, Patel MN, Chaudry G, Wentzel MS, Mobberley-Schuman PS, Campbell LM, Brookbank C, Gupta A, Chute C, Eile J, McKenna J, Merrow AC, Fei L, Hornung L, Seid M, Dasgupta AR, Dickie BH, Elluru RG, Lucky AW, Weiss B, Azizkhan RG. Efficacy and safety of sirolimus in the treatment of complicated vascular anomalies. Pediatrics 2016; 137:e20153257.

13. Akbayrak T, Orhan C, Baran E, Kaya S, Coskun G, Varan A. Effects of physiotherapy combined with sirolimus in a patient with vascular malformation: A case report. Turk $\mathbf{J}$ Pediatr 2016;58:203-207.

14. Akyüz C, Ataş E, Varan A. Treatment of a tongue lymphangioma with sirolimus after failure of surgical resection and propranolol. Pediatr Blood Cancer 2014; 6:931-932.

15. Alemi AS, Rosbe KW, Chan DK, Meyer AK. Airway response to sirolimus therapy for the treatment of complex pediatric lymphatic malformations. Int J Pediatr Otorhinolaryngol 2015; 79:2466-2469.

16. Altawil L, Neel NF, Alhedyani A, Badran M, Alokaili R, AlAjlan S. Neutropenia in sirolimus treated patients of lymphatic malformation: A case series. J Case Rep 2017; 7: 169-173.

17. Azouz H, Salah H, Al-Ajlan S, Badran M. Treatment of cystic hygroma in a young infant through multidisciplinary approach involving sirolimus, sclerotherapy, and debulking surgery. JAAD Case Rep 2016; 2:350-353.

18. Boon LM, Hammer J, Seront E, Dupont S, Hammer F, Clapuyt P, Vikkula M. Rapamycin as novel treatment for refractory-to-standard-care slow-flow vascular malformations. Plast Reconstr Surg 2015; 136:38.

19. Ersoy AO, Oztas E, Saridogan E, Ozler S, Danisman N. An unusual origin of fetal lymphangioma filling right axilla. J Clin Diagn Res 2016; 10:QD09-QD11.

20. Escoda AC, Ramos ML, Suárez JA, Celma MS, Heredia AC, PassinicVPC. Use of sirolimus in a newborn affected by lymphatic malformation. Eur J Hosp Pharm 2017; 24: A130-A131.

21. Lackner H, Karastaneva A, Schwinger W, Benesch M, Sovinz P, Seidel M, Sperl D, Lanz S, Haxhija E, Reiterer F, Sorantin E, Urban CE. Sirolimus for the treatment of children with various complicated vascular anomalies. Eur J Pediatr 2015; 174:1579-1584.

22. Margolin JF, Soni HM, Pimpalwar S. Medical therapy for pediatric vascular anomalies. Semin Plast Surg 2014; 28 : 79-86.

23. Roessler J, Niemeyer CM. Sirolimus is highly effective for lymph leakage in microcystic lymphatic malformations with skin involvement. Int J Dermatol 2017; 56:e71-e88.

24. Triana P, Dore M, Cerezo VN, Cervantes M, Sánchez AV, Ferrero MM, González MD, Lopez-Gutierrez JC. Sirolimus in the Treatment of Vascular Anomalies. Eur J Pediatr Surg 2017; 27:86-90.

25. Tschauner S, Sorantin E, Haxhija E. Überprüfung systemischer Sirolimus-Therapie zystischer Lymphangiome mittels MRT-Methodenbeschreibung anhand von vier klinischen Fällen. Fortschr Röntgenstr 2013; 184:884-901.

26. Yesil S, Bozkurt C, Tanyildiz HG, Tekgunduz SA, Candir MO, Toprak S, Sahin G. Successful treatment of macroglossia due to lymphatic malformation with sirolimus. Ann Otol Rhinol Laryngol 2015; 124:820-823.

27. Kim D, Benjamin L, Wysong A, Hovsepian D, Teng J. Treatment of complex periorbital venolymphatic malformation in a neonate with a combination therapy of sirolimus and prednisolone. Dermatol Ther 2015; 28:218221.

28. Lindberg M, Casey RK, Gomez-Lobo V. Treatment of vaginal venolymphatic malformation with sirolimus in a 2-year-old girl. J Pediatr Adolesc Gynecol 2016; 29:173174.

29. Yesil S, Tanyildiz HG, Bozkurt C, Cakmakci E, Sahin G. Single-center experience with sirolimus therapy for vascular malformations. Pediatr Hematol Oncol 2016; 33:219225.

30. Vlahovic AM, Vlahovic NS, Haxhija EQ. Sirolimus for the treatment of a massive capillary-lymphatico-venous malformation: A case report. Pediatrics 2015; 136:e513e516.

31. Danial C, Tichy AL, Tariq U, Swetman GL, Khuu P, Leung TH, Benjamin L, Teng J, Vasanawala SS, Lane AT. An open-label study to evaluate sildenafil for the treatment of 
lymphatic malformations. J Am Acad Dermatol 2014; 70: 1050-1057.

32. Maruani A, Brown S, Lorette G, Pondaven-Letourmy S, Herbreteau D, Eisenbaum A. Lack of effect of propranolol in the treatment of lymphangioma in two children. Pediatr Dermatol 2013; 30:383-385.

33. Rankin H, Zwicker K, Trenor CC 3rd. Caution is recommended prior to sildenafil use in vascular anomalies. Pediatr Blood Cancer 2015; 62:2015-2017.

34. Swetman GL, Berk DR, Vasanawala SS, Feinstein JA, Lane AT, Bruckner AL. Sildenafil for severe lymphatic malformations. N Engl J Med 2012; 366:384-386.

35. Wu JK, Hooper ED, Laifer-Narin SL, Simpson LL, Kandel J, Shawber CJ; Lymphatics Work Group at CUMC. Initial experience with propranolol treatment of lymphatic anomalies: A case series. Pediatrics 2016; 138: pii: e20154545.

36. Luo Y, Liu L, Rogers D, Su W, Odaka Y, Zhou H, Chen W, Shen T, Alexander JS, Huang S. Rapamycin inhibits lymphatic endothelial cell tube formation by down- regulating vascular endothelial growth factor receptor 3 protein expression. Neoplasia 2012; 14:228-237.
37. Yu JH, Kim KW, Kim BM, Chung BH, Cho ML, Choi BS, Park CW, Kim YS, Yang CW. Safety and immunologic benefits of conversion to sirolimus in kidney transplant recipients with long-term exposure to calcineurin inhibitors. Korean J Intern Med 2016; 31:552-559.

38. Martel R, Klicius J, Galet S. Inhibition of the immune response by rapamycin, a new antifungal antibiotic. Can J Physiol Pharmacol 1977; 55:48-51.

39. Kaplan B, Qazi Y, Wellen JR. Strategies for the management of adverse events associated with mTOR inhibitors. Transplant Rev (Orlando) 2014; 28:126-133.

Address correspondence to: Susanne Wiegand, MD Department of Otolaryngology Head and Neck Surgery University of Leipzig Liebigstrasse 12 Leipzig 04103

Germany

E-mail: susanne.wiegand@medizin.uni-leipzig.de 